\title{
Characteristics and outcomes of health and social care workers testing positive for SARS-CoV-2 in the Tayside region of Scotland
}

To the Editor:

The spread of severe acute respiratory syndrome coronavirus 2 (SARS-CoV-2) and reported outcomes among health and social care workers (HSCWs) is concerning [1-3]. Early in the outbreak it was recommended in the UK that HSCWs experiencing symptoms of a cough or fever remain absent from work for 7 days. In order to address this problem, National Health Service (NHS) Tayside, a health board in Scotland covering a population of 400,000, was the first in Scotland to set up a drive-through testing programme for HSCWs, other key workers and their symptomatic household contacts (including children), with results available within $24 \mathrm{~h}$, allowing staff to return to work following a negative test [4]. As testing for SARS-CoV-2 was limited to hospitalised patients across much of Europe there is limited data on the self-reported clinical characteristics and outcomes of patients in the community with coronavirus disease 2019 (COVID-19). Here, we report characteristics and outcomes of HSCWs presenting to the drive-through testing centre who tested positive for SARS-CoV-2 on a combined nasal and pharyngeal swab. Anonymised record linkage was conducted between routinely collected healthcare datasets in order to ascertain clinical characteristics and outcomes of those who tested positive. All hospitalisations until 25 April and deaths until 20 May, 2020 were recorded. Approval was obtained from the local data protection officer (Caldicott Guardian).

Between 17 March, 2020 and the 27 April, 2020, 2993 symptomatic HSCWs in NHS Tayside were tested for SARS-CoV-2 through the drive-through facility with 677 (22.6\%) of these testing positive (figure 1). Of those who tested positive, $45 \%$ presented with a fever, $70 \%$ a cough and $9 \%$ experienced shortness of breath. $32 \%$ reported both a fever and cough. Mean \pm SD age of those who tested positive was $44.7 \pm 20$ ) and $77 \%$ were female. Overall, the burden of comorbidity was low in this group: $3.7 \%$ had diabetes; $2.2 \%$ had COPD; 5.9\% had ischaemic heart disease; nobody had chronic kidney disease; $5.9 \%$ had been treated with lipid lowering treatment and 25\% anti-hypertensive medications.

Hospitalisations were recorded using the new ICD code for COVID-19: U07.1 [5] Eight individuals were hospitalised (the majority of which were for $24 \mathrm{~h}$ or less). The average time between a positive PCR test and hospitalisation was 4 days for males and 7 for females. There were fewer than five deaths (number suppressed due to potential identifiable disclosure). We did not have access to data on ethnicity, but the population covered by NHS Tayside is $99 \%$ white ethnicity with $97 \%$ of NHS Tayside staff workers recorded as being of white ethnicity in 2019.

We have found that in a predominately low comorbid white population of symptomatic HSCWs self-presenting to a drive through testing facility, there was a relatively high prevalence of SARS-CoV-2. However, this was associated with mild disease in the majority of cases. Not only does this approach to staff testing minimise workforce depletion, but also, no doubt plays a role in reducing transmission of SARS-CoV-2 in hospitals and care facilities [6].

@ERSpublications

Tayside, Scotland was one of the first health boards to institute testing for all symptomatic workers. As expected, there was a high prevalence of SARS-CoV-2 among health and social care workers; however, in most cases disease was mild. https://bit.ly/38JaUmB

Cite this article as: Siddiqui MK, Parcell B, Allstaff S, et al. Characteristics and outcomes of health and social care workers testing positive for SARS-CoV-2 in the Tayside region of Scotland. Eur Respir J 2020; 56: 2002568 [https://doi.org/10.1183/13993003.02568-2020]. 


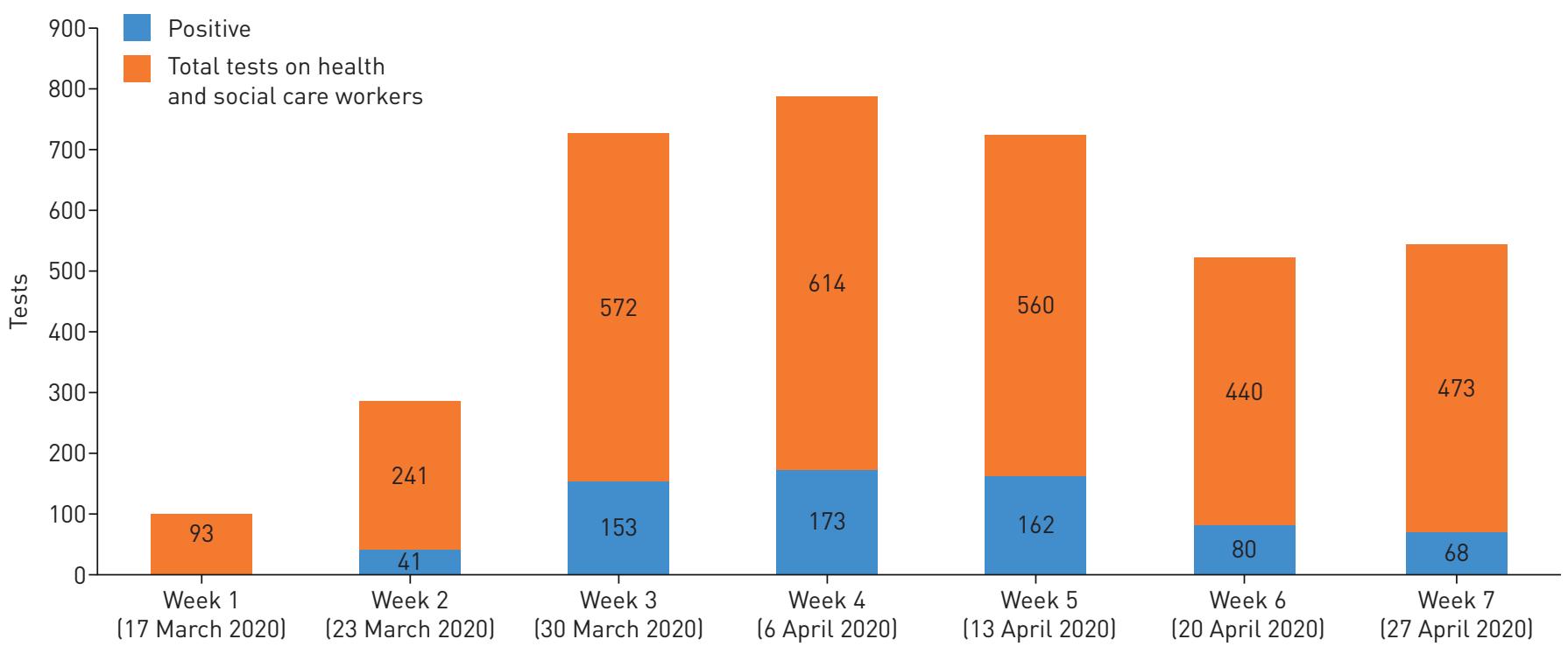

FIGURE 1 Proportion of positive tests in health and social care workers in Tayside, Scotland. Percent positive for week $2-7$ were $17 \%, 27 \%, 28 \%$, $29 \%, 18 \%$ and $14 \%$ respectively. There were no recorded positive tests in the first week of testing.

Moneeza K. Siddiqui $\odot^{1}$, Benjamin Parcell ${ }^{2}$, Sarah Allstaff ${ }^{3}$, Colin Palmer ${ }^{1}$, James D. Chalmers ${ }^{4}$ and Samira Bell ${ }^{1}$ ${ }^{1}$ Division of Population Health and Genomics, School of Medicine, University of Dundee, Dundee, UK. ${ }^{2}$ Dept of Medical Microbiology, Ninewells Hospital and Medical School, Dundee, UK. ${ }^{3}$ Tayside Sexual and Reproductive Health Service, Ninewells Hospital and Medical School, Dundee, UK. ${ }^{4}$ Division of Molecular and Clinical Medicine, School of Medicine, University of Dundee, Dundee, UK.

Correspondence: James D. Chalmers, Division of Molecular and Clinical Medicine, School of Medicine, University of Dundee, Dundee, DD1 9SY, UK. E-mail: j.chalmers@dundee.ac.uk

Received: 30 June 2020 | Accepted: 3 July 2020

Conflict of interest: M.K. Siddiqui has nothing to disclose. B. Parcell has nothing to disclose. S. Allstaff has nothing to disclose. C. Palmer has nothing to disclose. J.D. Chalmers has received research grants from GlaxoSmithKline, Boehringer Ingelheim, AstraZeneca, Pfizer, Grifols, Bayer AG, Polyphor and Insmed; and received consultancy, congress travel or speaker fees from GlaxoSmithKline, Bayer Healthcare, Aradigm Corporation, Grifols, Pfizer, Boehringer Ingelheim, Napp and Insmed. S. Bell has nothing to disclose.

\section{References}

1 The Lancet. COVID-19: protecting health-care workers. Lancet 2020; 395: 922.

2 Prescott K, Baxter E, Lynch C, et al. COVID-19: how prepared are front-line healthcare workers in England? J Hosp Infect 2020; 105: 142-145.

3 World Health Organization. WHO Coronavirus Disease (COVID-19) Situation Report - 84. www.who.int/docs/ default-source/coronaviruse/situation-reports/20200413-sitrep-84-covid-19.pdf?sfvrsn=44f511ab_2 Last updated: 13 April 2020.

4 Parcell B, Brechin K, Allstaff S, et al. Drive-through testing for SARS-CoV-2 in symptomatic health and social care workers and household members: an observational cohort study in Tayside, Scotland. medRxiv 2020; preprint [https://doi.org/10.1101/2020.05.08.20078386].

5 World Health Organization. Emergency Use ICD Codes for COVID-19 Disease Outbreak. https://www.who.int/ classifications/icd/covid19/en/ Last updated: 20 April 2020.

6 Black JRM, Bailey C, Przewrocka J, et al. COVID-19: the case for health-care worker screening to prevent hospital transmission. Lancet 2020; 395: 1418-1420. 